\title{
Trend of Gini coefficient of healthcare resources in China from 1998 to 2016
}

\author{
Yuchen Yang ${ }^{1}$, Yasuhiro Morii ${ }^{2}$, Kensuke Fujiwara ${ }^{2,3}$, Tomoki Ishikawa ${ }^{2,4}$, Hiroko Yamashina ${ }^{2}$, \\ Teppei Suzuki ${ }^{2,5}$, Jun Nakaya ${ }^{2}$, Katsuhiko Ogasawara ${ }^{2}$ \\ ${ }^{1}$ Graduate School of Health Sciences, Hokkaido University, Sapporo, Japan; ${ }^{2}$ Faculty of Health Sciences, Hokkaido University, Sapporo, Japan; \\ ${ }^{3}$ Graduate School of Commerce, Otaru University of Commerce, Otaru, Japan; ${ }^{4}$ Institute for Health Economics and Policy, Tokyo, Japan; \\ ${ }^{5}$ Iwamizawa Campus, Hokkaido University of Education, Iwamizawa, Japan \\ Contributions: (I) Conception and design: Y Yang, Y Morii; (II) Administrative support: K Ogasawara, J Nakaya; (III) Provision of study materials or \\ patients: H Yamashina; (IV) Collection and assembly of data: Y Yang; (V) Data analysis and interpretation: Y Yang, Y Morii, T Ishikawa, K Fujiwara, \\ T Suzuki; (VI) Manuscript writing: All authors; (VII) Final approval of manuscript: All authors. \\ Correspondence to: Katsuhiko Ogasawara. Faculty of Health Sciences, Hokkaido University, N12-W5, Kita-ku, Sapporo 060-0812, Japan. \\ Email: oga@hs.hokudai.ac.jp.
}

Background: Healthcare disparities in China are attracting attention not only in the country but also worldwide. However, few studies have evaluated the changes in equality of healthcare resource distribution among provinces in China. This study was conducted to provide healthcare resource allocation advice to government medical management institutions. We aimed to (I) analyze changes in healthcare disparities in China from 1998 to 2016 through data visualization and (II) determine what factors are related to the changes.

Methods: We evaluated healthcare disparities in China by collecting statistical data on healthcare in China from 1998 to 2016 and calculating the Gini coefficient of healthcare resource distribution among the provinces, and comparatively observed the trend of Gini coefficient. Data used in this study were taken from the China Statistical Yearbook (1999-2017).

Results: From 2008 to 2016, the Gini coefficient for doctors and nurses dropped by 0.048 (39.4\%) and $0.058(40.9 \%)$, respectively. The increase rate of number of nurses is the highest (109.0\%), and at the same time, the distribution of nurses is also the most significant. On the other hand, since 2002, the Gini coefficient of healthcare institutions has fluctuated between 0.150 and 0.200 . few changes were found in number of medical institutions.

Conclusions: Since 2004, the distribution of health human resource has been improving due to the abundance of healthcare resources in China; however, the distribution of healthcare institutions has not been improving. We consider that the enrichment of medical resources has a positive impact on the distribution of human resources, but not on the distribution of physical and financial resources. This situation is considered to be one of the results of several health issues in China, such as the existence of super hospitals with thousands of beds in the inland areas, which interferes with the establishment of China's hierarchical medical system.

Keywords: Gini coefficient; healthcare disparities; China's healthcare; health economics; healthcare resourcing

Received: 29 June 2020; Accepted: 02 April 2021; Published: 25 December 2021.

doi: 10.21037/jhmhp-20-93

View this article at: http://dx.doi.org/10.21037/jhmhp-20-93 


\section{Introduction}

Since the reform and opening-up policies were first implemented, the economy of China has achieved remarkable development. Although healthcare reform in China has achieved many improvements in recent years, there is still room for improvement with regard to equal access to healthcare resources and services. As the country with the world's largest population, China has relatively insufficient medical and economic resources, particularly in rural and remote areas (1). Since early 1980s, much of the responsibility for funding healthcare services has been transferred from central government to provincial and local authorities, which means that medical institutions in wealthy coastal provinces are likely to receive more funding and resources than less wealthy inner provinces (2). Disparities in healthcare resources and services are factors that affect health status and quality of life $(3,4)$. The research on equity in healthcare services has been specified by the Chinese government as one of the key indicators of evaluation criteria for medical systems $(5,6)$. An urgent issue is how to provide accessible and affordable healthcare services to poor and rural people based on social health insurance policies that benefit the entire society (7).

Previous studies have suggested that the abundance of healthcare resources in a region is strongly related to the economic situation of that region (8-10). According to a study by Matsumoto et al., between 1995 and 2010, the number of doctors per population in the United States and Japan increased by $55 \%$ and $47 \%$, respectively; however, there was little increase in the equity of the distribution in either of the countries. In the United States in particular, the relationship between the number of doctors per unit population and per capita income in the community was stronger than in Japan and tended to be stronger in there research period (8). Hahm et al. reported that the prevalence of magnetic resonance imaging (MRI) scans in each region in Korea was positively correlated with the number of physicians per person, average taxable income, and the population over the age of 65 in the region (9). Another study in Korea worked by Chang and Kim showed medical resources reduce age-standardized mortality rate, with medical facilities having the greatest influence followed by specialists, then by high-end medical equipment (10). In Japan, a study by Suzuki et al. classified Organization for Economic Co-operation and Development member countries into four types, based on their potential for growth in the healthcare market and for the development of their economic environment. Suzuki et al. speculated that the possibility of introducing computed tomography and MRI scans was influenced not only by economic growth but also by the number of beds per person (11).

Within China, a study by Xie and Zhou showed that a large proportion of China's significant income inequality is due to regional and rural-urban disparities (12). In 2010, a study by Fang et al. reported that there existed distinct regional disparities in health in China, which was increasing with the rapid economic growth. The regional health inequality was associated with not only the distribution of wealth, but also the distribution of health resources and primary healthcare services (13). With regard to healthcare resources, $\mathrm{Lu}$ and Zeng analyzed inequalities in the geographical distribution of traditional medicine-related healthcare resources in China. The authors showed that the number of beds and doctors per unit population was even, although the distribution of the hospital beds and doctors per $\mathrm{km}^{2}$ was uneven, which revealed a large gap (14). A study by $\mathrm{He}$ et al. assessed the fairness of the distribution of computed tomography and MRI services among the five provinces of China and found that these services were concentrated in rich areas (15). Other studies by Yan et al. and Zhang et al. analyzed the current situation of rural-urban disparities in healthcare resources in China (16,17). Fan et al. reported that there were significant health differences in the elder population on an inter-provincial level, and nearly $2.4 \%$ of these health differences in the elder population were caused by inter-provincial inequalities (18). Zhu et al. assessed the changes of regional disparities in traditional Chinese medical (TCM) healthcare resources before and after 2009 healthcare reforms, and reported that although TCM hospital number, scale, and doctors' workload increased in 2004-2016, the regional disparities in healthcare resources, especially between the eastern and western regions, were not significantly changed (19). However, few studies have assessed the equality of healthcare resource distribution among provinces in China through the visualization of changes by year in Gini coefficient. To provide healthcare resource allocation advice to government healthcare management institutions, we aimed to (I) analyze changes in healthcare disparities in China from 1998 to 2016 through data visualization and (II) determine the factors related to the changes.

We present the following article in accordance with the MDAR reporting checklist (available at http://dx.doi. org/10.21037/jhmhp-20-93). 


\section{Methods}

\section{Data}

Data used in this study were taken from the China Statistical Yearbook (1999-2017) (16). The Cbina Statistical Yearbook is a publication that collects and integrates national data for the current year from the China National Bureau of Statistics. The partially missing data were replaced by the data published in the Cbina Health Statistics Yearbook (17) (published by the National Health Commission of China) or the National Statistics Bureau website. In addition, because we could not obtain data for Hong Kong, Macao and Taiwan, they were excluded from this study.

The Gini coefficient was calculated using population, regional total production, the number of medical personnel, the number of doctors, the number of nurses (the data for 1998 is missing), the number of beds of medical institutions, the number of medical institutions, the number of hospitals, and the number of clinics (change in statistical method since 2010) to evaluate the disparities among 31 provinces in China from 1998 to 2016.

According to China Statistical Yearbook, medical technical personnel were defined as "all medical specialists (including apprentices) such as practicing physicians, practicing assistant physicians, nurses, pharmacists, laboratory technicians, radiologists and hygienists", and doctors were defined as the "person in charge of duties in medical care and preventive health institution and who got qualification of practitioner or practice assistant doctor" $(20,21)$.

In addition, in this study, the term "clinic" refers to the functions of primary care and preventive health institutions at the grassroots level such as a community health service center, township health center, or "village clinic" established by the government, as well as clinics in the general sense. The "village clinic" is a healthcare institution that has been established in nearly each village of rural area to provide rudimentary healthcare services. As the statistical data of the village clinics for each province were first recorded in Cbina Statistical Yearbook 2010, analysis on the number of medical institutions and clinics has been conducted since 2009, both with and without data from the village clinics.

\section{Statistical analysis}

The Gini coefficient was used to assess medical disparities. The Gini coefficient is an indicator that measures the inequality of income distribution mainly in society. In recent years, the Gini coefficient has been used to study cases of uneven distribution of resources and inequality in energy consumption. The importance of the measure in public health and epidemiology has also been recognized.

In this study, Gini coefficients are calculated using the following formula:

$$
\mathrm{G}=1-\sum_{\mathrm{i}=1}^{\mathrm{n}}\left(\mathrm{N}_{\mathrm{i}}+\mathrm{N}_{\mathrm{i}-1}\right)\left(\mathrm{M}_{\mathrm{i}}-\mathrm{M}_{\mathrm{i}-1}\right)
$$

In this formula, $\mathrm{N}$ is the number of regional data (in this research, $\mathrm{N}=31$ ), $\mathrm{I}$ is the order of the region in which the data per unit population are arranged in order from low to high, $N_{i}$ is the cumulative ratios of medical resources data, and $M_{i}$ is the cumulative ratios of population data $\left(\mathrm{N}_{0}=\mathrm{M}_{0}=0\right)$.

Gini coefficient scores range from 0 to 1 . The lower the score is, the smaller the medical disparity is. Because the target of this study was the 31 province-level administrative areas in China, the Gini coefficient scores in this study represent only inter-province differences, and the disparities present within each province are not included.

\section{Results}

\section{Distribution disparity in human resources among the provinces}

Figure 1 shows the changes in the number and annual growth rates of medical technical personnel, doctors, nurses, and beds owned by healthcare institutions during the period from 1998 to 2016.

With the revision of the statistical method in 2002, the number of medical technical personnel decreased because physicians who did not obtain medical qualifications by passing the national examination and nurses who were not registered with the health department of government were excluded from the statistical data. Doctors who did not pass the original National Practitioner Examination of China in 1999 were excluded from the statistics, which caused a significant reduction in the number of doctors (the annual growth rate was $-12.18 \%$ ) at these institutions. The same revision also reduced the number of healthcare institutions, and therefore the number of beds owned by these institutions decreased accordingly.

The annual growth rates (not including 2002) show that the number of medical technical personnel changed very little by 2004 (increasing to 4.5 million); however, the growth rates have risen since 2005. Between 2008 and 2016, the number of medical technical personnel increased from 5.17 to 8.45 million (with a rate of increase of $63.39 \%$ ), the number of doctors increased from 2.20 to 3.20 million (with 


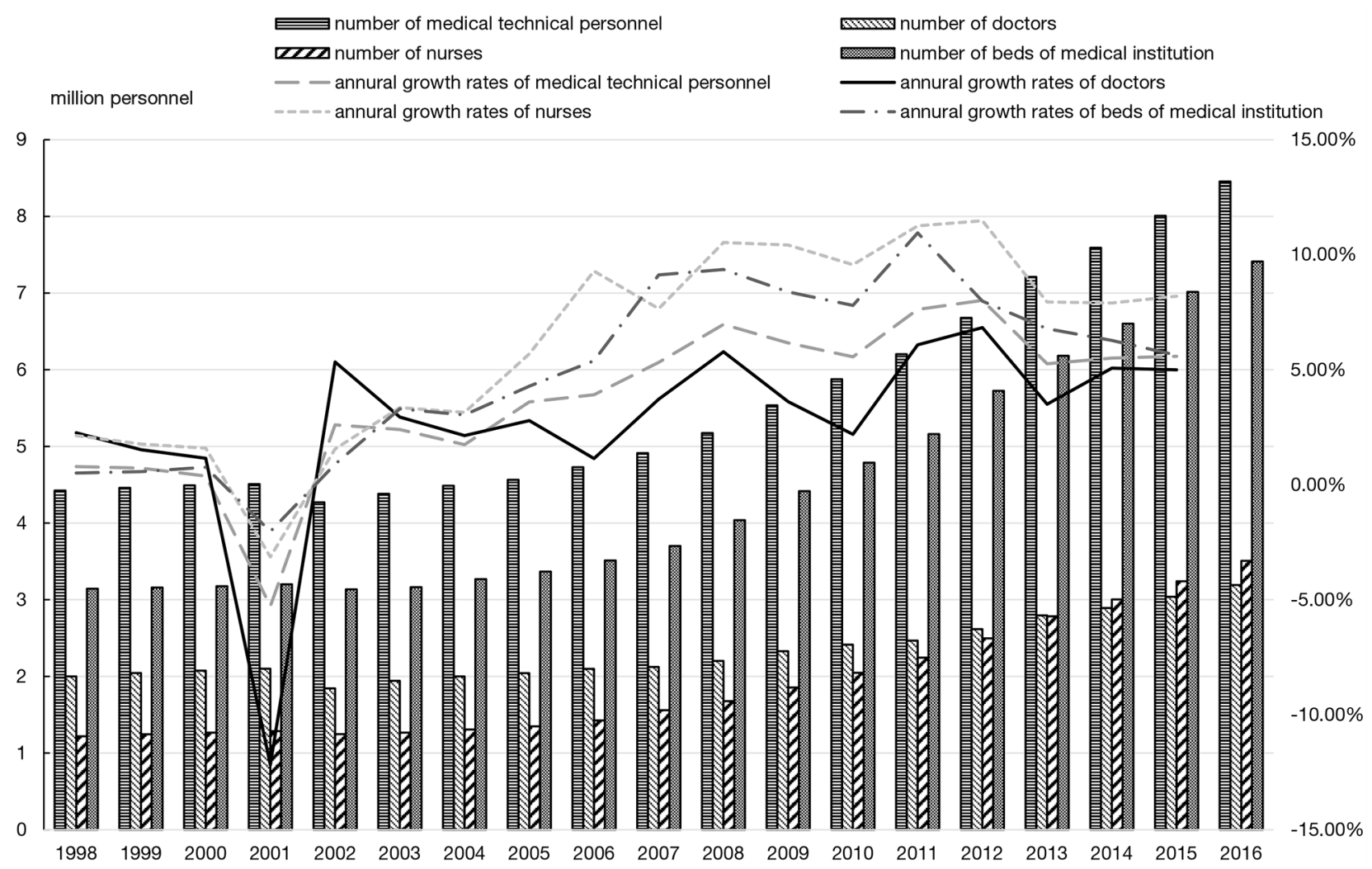

Figure 1 Trends and annual growth rates in the number of medical technical personnel, doctors, nurses, and beds owned by healthcare institutions in China from 1998 to 2016.

a rate of increase of $44.92 \%$ ), and the number of nurses increased from 1.68 to 3.50 million (with a rate of increase of $109.00 \%)$. Annual growth rates for the number of doctors were consistently low (only up to 6\%). In contrast, the average annual growth rate for the number of nurses was over 10\% between 2008 and 2012. As a result, although the number of nurses had long been lower than the number of doctors in China, it has exceeded the number of doctors since 2013.

Figure 2 shows the annual trends of population-based Gini coefficients in numbers of medical personnel, doctors, nurses, and beds owned by healthcare institutions. For illustrating the economic development disparity, the Gini coefficient of regional gross domestic product is represented.

Between 1999 and 2016, the Gini coefficient for the number of nurses was the highest ever among the four Gini coefficients, suggesting that regional disparity of nurses was the most significant. Because the Gini coefficient changed from 0.196 to 0.083 , the improvement of the distribution was also the most remarkable among the four Gini coefficients. Other than the Gini coefficient of the number of nurses, the other Gini coefficients were basically 0.130 to 0.159 between 1998 and 2004, but they gradually decreased from 2004, and in 2016, all three were around 0.072. Besides, the Gini coefficient of beds distribution has risen to bounce back from 2013. At the same time, the Gini coefficient of regional gross domestic product, which represented economic disparity, continued to decrease after reaching a peak in 2003, and showed a similar trend as it rebounds slightly from 2013.

\section{Distribution disparity in physical and financial resources among 31 provinces}

Table 1 shows the number of healthcare institutions (excluding village clinics, the same below), hospitals, village clinics (data in 2002 is missed) and their annual growth rates from 1998 to 2016.

The number of healthcare institutions decreased around 


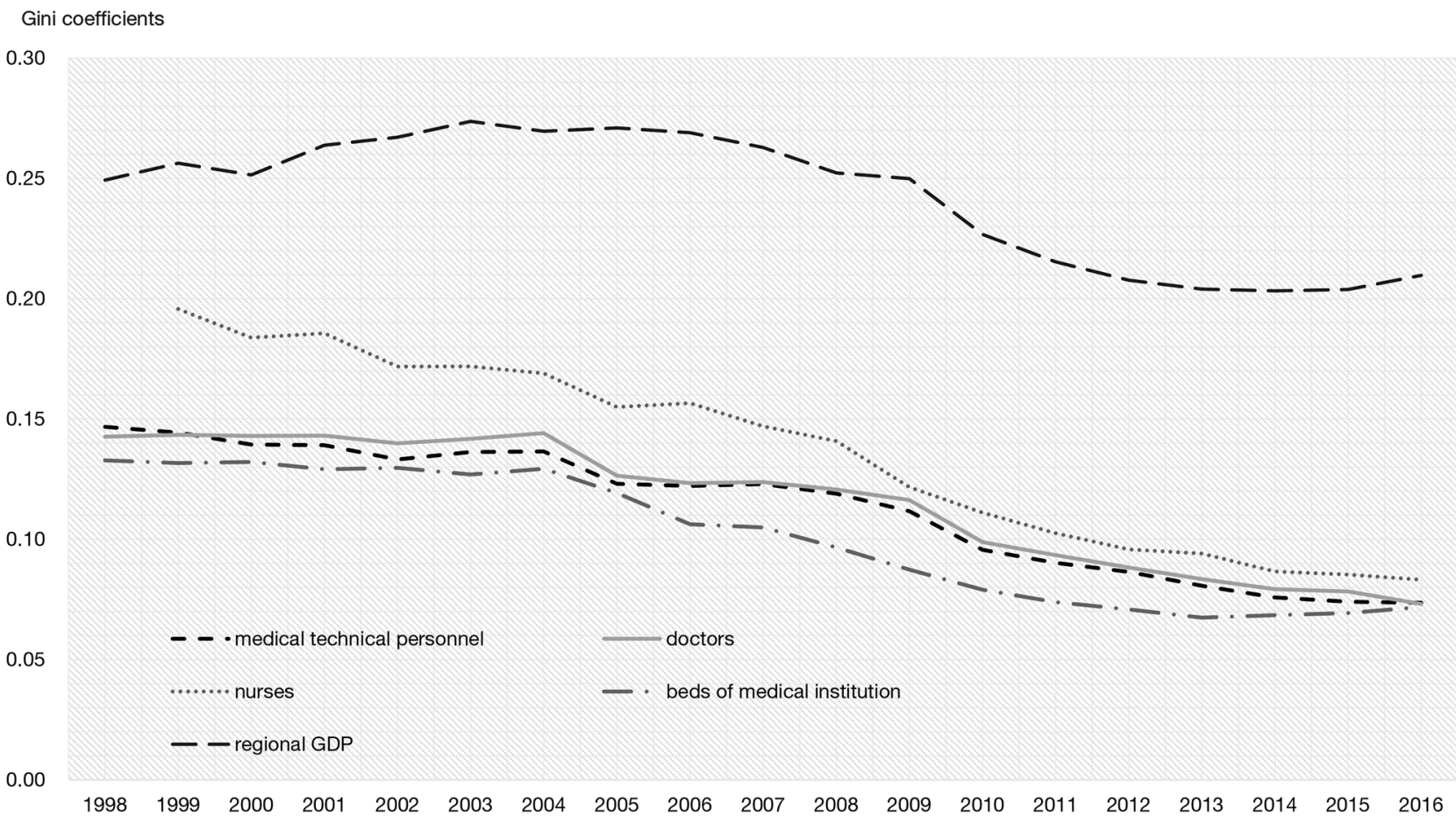

Figure 2 Annual trend of population-based Gini coefficients in numbers of medical technical personnel, doctors, nurses, and beds of medical institution in China from 1998 to 2016.

2000 and between 2007 and 2008 but has tended to increase since 2010. The pace of increase was particularly rapid for the number of hospitals from 2010, with an average annual growth rate exceeding $5 \%$. On the other hand, the change in the number of village clinics has been recognized as a "big wave" and has decreased gradually since 2012 .

Figure 3 shows the annual trend of population-based Gini coefficients in numbers of healthcare institutions and hospitals.

The data indicate that there is no trend toward improvement in equality with regard to the distribution of healthcare institutions and hospitals among provinces. Since 2002, the Gini coefficient of healthcare institutions has fluctuated between 0.150 and 0.200 . According to the data since 2009, the population-based Gini coefficient in healthcare institutions was higher when the data on village clinics were included. In addition, although the number of hospitals has been increasing at a rapid pace since 2010, the Gini coefficient shows no tendency to decline.

\section{Discussion}

Figure 1 shows that human resource distribution has improved since 2004. This improvement is considered to be largely due to the severe acute respiratory syndrome (SARS) epidemic of 2003 (1). The sanitation policy in China at that time of the outbreak was strongly shaken, and many problems such as poor maintenance of the epidemic prevention system and inequality of medical resources were exposed (22). Since 2004, the number of doctors and nurses has been increasing rapidly, and at the same time the distribution of medical technical personnel among provinces has begun to improve. From 2008 to 2016, the total number of doctors nationwide increased by $44.92 \%$ (2.20 to 3.20 million), and the total number of nurses increased by $109.00 \%$ (1.68 to 3.51 million), whereas the increase of the total population was only $4.12 \%$ (1,328.02 to $1,382.71$ million). As a result, the Gini coefficient for doctors and nurses dropped by 0.048 (39.4\%) and 0.058 (40.9\%), respectively. While the growth rate of nurses is above that of doctors, improvement in nurses' distribution is also relatively significant. Based on the description above, it is thought that the distribution among provinces of medical human resources has improved as the ratio of the number of medical personnel to the population in China rises. These results suggest that the distribution of human resources for medical care among provinces in 
Table 1 Annual trends and growth rates in number of medical institutions, hospitals and village clinics in China from 1998 to 2016

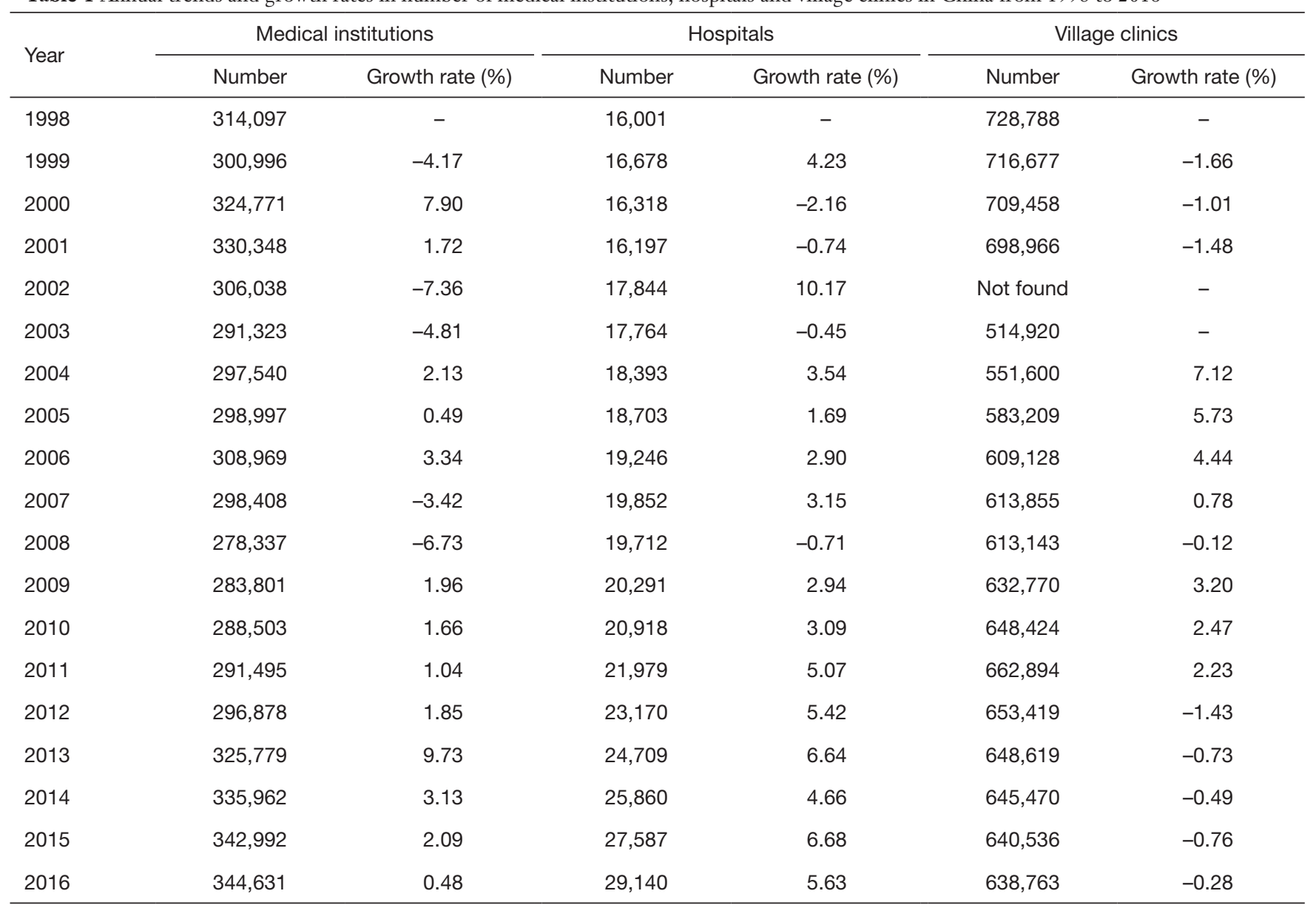

China supports the spatial competition hypothesis $(23,24)$. Because the economic disparities among provinces have been decreasing since 2003, the distribution improvement of human resources maybe also affected by the improvement of economic disparities.

However, thought here has been improvement in human resource distribution, equality of medical institution distribution has not shown a tendency to improve. This phenomenon which is called "syphon effect" by Chinese critics and scholars could indicate that when new human resources are introduced into areas that were originally poor in medical resources, the resource tend to concentrate on existing medical institutions rather than create new ones (25). It can be thought that this tendency was caused by the existence of "super hospitals" in the inland areas where economic and medical resources were scarce. The term super hospital refers to a large hospital that has more than a thousand beds (26), and the medical resources possessed by the super hospital dominate the region. There are more than 10 single hospitals have more than 4,000 beds in China (27). The super hospital has the state-of-the-art medical equipment to treat patients with incurable diseases such as cancer, but at the same time a large number of common diseases (such as cold) patients are also crowded with their outpatient departments (28). Such a phenomenon can objectively improve the level of healthcare services in the area quickly and can offer a good environment for the training of medical personnel training, but on the other hand, the servicing of patients is achieved by concentrating almost all patients in one hospital. As the rooms and wards become crowded, the efficiency and quality of care provided decreases. In addition, for super hospitals to continue to exist, a substantial amount of money is required, which means that sales will be pursued, which may cause more physician-induced demand (26). Lastly, treating almost all patients regardless of the type and severity of the disease interferes with the establishment of the 


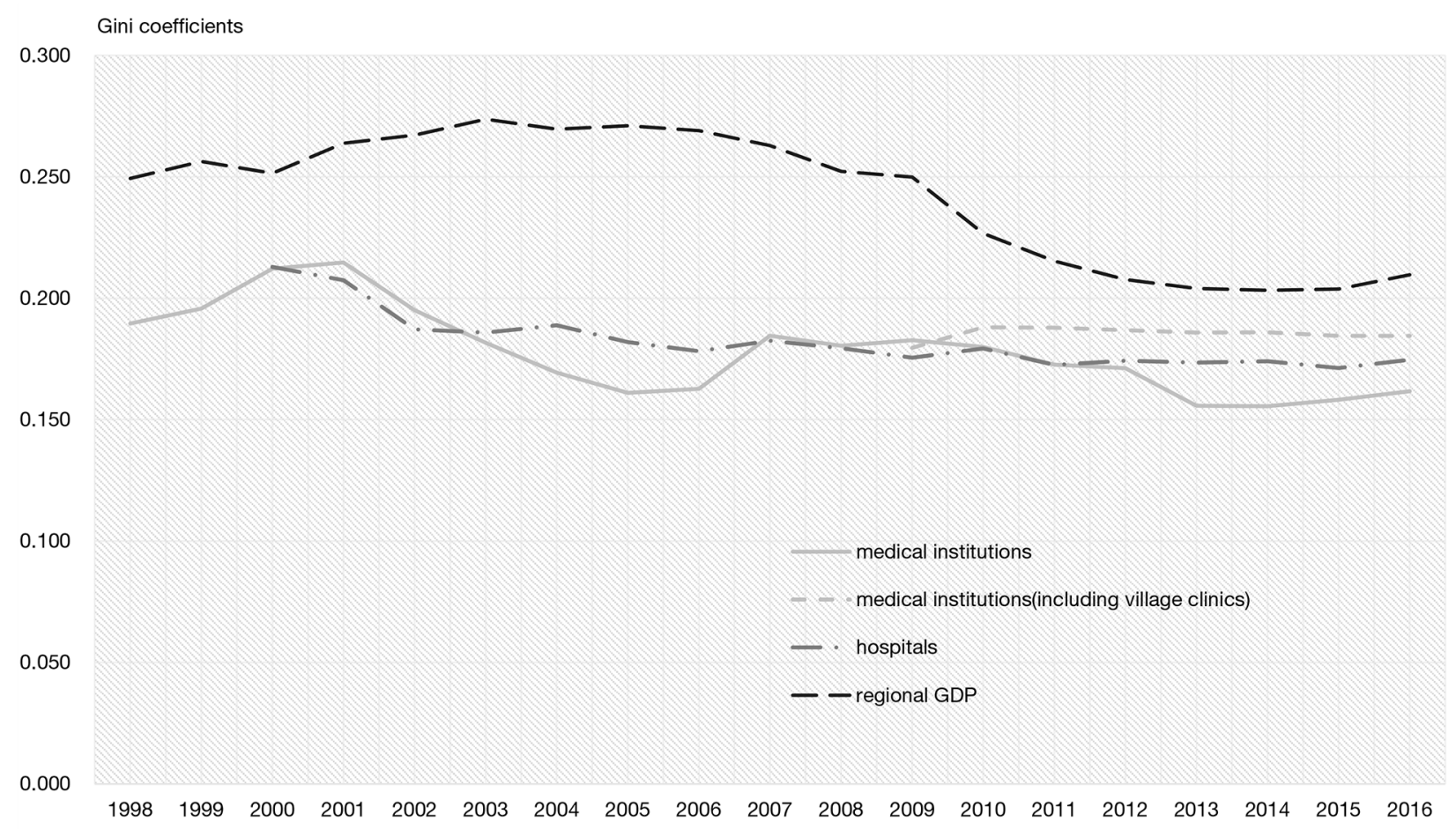

Figure 3 Annual trend of Gini coefficient in the number of medical institutions and hospitals among provinces in China (1998-2016).

hierarchical medical system that has recently been discussed in social and government reports (25).

In rural areas, the distribution of healthcare institutions when village clinics (which provide only minimal medical services) are included is inferior to the distribution of these institutions when village clinics are excluded. The number of village clinics in Central and Western China is large in order to cover almost all villages that scattered throughout a wide range of rural areas but is small in Eastern China with large cities and populations (29). It is believed that the village clinic may have a greater impact on area-based equality than population-based equality. Further research will warrant this matter. A study by Jin et al. showed that the Gini coefficients by geographical area in China indicate more inequality than demographical, which is a result of the sparsity of population (30).

\section{Limitations}

In this study, healthcare equality was calculated based solely on the population, but it also relates to the area and the epidemiological situation of the region (17). The interprovincial Gini coefficient of the distribution of medical resources in China listed in this study is to regard the average medical per 1,000 population in the region as the abundance of medical resources in the region, while ignoring the differences in the distribution of medical resources within the region. Actually, in China, there is a huge uneven distribution of resources and economy between towns and villages in almost any region (usually, province) (31). Wu and Yang pointed out that Intra-regional disparities within the east, central, and western regions were the main cause for overall demographic inequality, whereas both intra-regional and inter-regional disparities significantly contributed to overall geographic inequality (32).

On the other hand, because of ignoring the uneven distribution within the region (province), the Gini coefficient calculated in this study is much smaller than the actual Gini coefficient of medical resources in China calculated in each person. For example, the Gini coefficient of doctors in the United States and Japan, as representatives of developed countries, was higher than 0.3 during 1980-2005, and there is no obvious downward trend (8). In that study, the data levels for the distribution of doctors were municipality-level for Japan and county-level for the United States. In that level, the average population was 
about 100,000 for each smallest data unit in both countries, compared with province-level in China with an average population of about 34 million. Lower data level usually means more detailed regional division and higher Gini coefficient value, which can better reflect the true situation of inequality distribution. At the same time, because it is difficult to divide other regions of the world into regions similar to China's administrative divisions in a reasonable method, it is not feasible to compare the Gini coefficients for other regions.

Finally, although the trend of inter-provincial Gini coefficient of the regional gross product (GRP) is marked in this study, there is no discussion about the relationship between changes in medical differences and changes in economic differences. Decomposition of the concentration index has been used by Li et al. and revealed that economic status was the primary contributor to the inequality of doctors and nurses (33), but there is no research on medical resources other than human resources yet. This question needs to be supplemented by the results of other studies.

\section{Conclusions}

In this study, we assessed healthcare resource disparity among 31 provinces in China by calculating populationbased Gini coefficients and visualizing the data. We found that though the distribution of human resources has been improving since 2004, the distribution of healthcare institutions has not shown a tendency to improve. This situation is considered to be one of the causes of some of China's most serious healthcare problems. With the completion of data bases and improvement of analysis methods, research on healthcare disparities may provide new perspectives or clues to solutions for healthcare problems in China.

\section{Acknowledgments}

Funding: None.

\section{Footnote}

Reporting Checklist: The authors have completed the MDAR reporting checklist. Available at http://dx.doi.org/10.21037/ jhmhp-20-93

Data Sharing Statement: Available at http://dx.doi. org/10.21037/jhmhp-20-93
Conflicts of Interest: All authors have completed the ICMJE uniform disclosure form (available at http://dx.doi. org/10.21037/jhmhp-20-93). KO serves as an unpaid editorial board member of fournal of Hospital Management and Health Policy from March 2020 to February 2022. The other authors have no conflicts of interest to declare.

Ethical Statement: The authors are accountable for all aspects of the work in ensuring that questions related to the accuracy or integrity of any part of the work are appropriately investigated and resolved.

Open Access Statement: This is an Open Access article distributed in accordance with the Creative Commons Attribution-NonCommercial-NoDerivs 4.0 International License (CC BY-NC-ND 4.0), which permits the noncommercial replication and distribution of the article with the strict proviso that no changes or edits are made and the original work is properly cited (including links to both the formal publication through the relevant DOI and the license). See: https://creativecommons.org/licenses/by-nc-nd/4.0/.

\section{References}

1. $\mathrm{Li} \mathrm{X}, \mathrm{Lu} \mathrm{J}, \mathrm{Hu} \mathrm{S}$, et al. The primary health-care system in China. Lancet 2017;390:2584-94.

2. Blumenthal D, Hsiao W. Privatization and its discontents-The Evolving Chinese Health Care System. N Engl J Med 2005;353:1165-70.

3. Cutler DM, Lleras-Muney A, Vogl T. The Oxford handbook of health economics. New York: Oxford University Press, 2011.

4. López-Casasnovas G, Rivera B, Currais L. editors. Health and economic growth: findings and policy implications. Cambridge: MIT Press, 2005.

5. Mao Y, Xu F, Zhang M, et al. Equity of health service utilization of urban residents: data from a western Chinese city. Chin Med J 2013;126:2510-6.

6. Chen $M$, Chen W, Zhao Y. New evidence on financing equity in China's health care reform-a case study on Gansu province, China. BMC Health Serv Res 2012;12:466.

7. Luo J, Zhang X, Jin C, et al. Inequality of access to health care among the urban elderly in northwestern China. Health Policy 2009;93:111-7.

8. Matsumoto M, Inoue K, Bowman R, et al. Geographical distributions of physicians in Japan and US: impact of healthcare system on physician dispersal pattern. Health Policy 2010;96:255-61. 
9. Hahm MI, Park EC, Lee SH, et al. Pattern and factors leading to the diffusion of magnetic resonance imaging in Korean hospitals. Int J Technol Assess Health Care 2007;23:292-8.

10. Chang I, Kim BHS. Regional disparity of medical resources and its effect on age-standardized mortality rates in Korea. Ann Reg Sci 2009;62:305-25.

11. Suzuki T, Isomi Y, Tsuji S, et al. Penetration factors and introduction possibility for image diagnostic equipment. Health Policy and Technology 2018;7:142-8.

12. Xie Y, Zhou X. Income inequality in today's China. Proc Natl Acad Sci U S A 2014;111:6928-33.

13. Fang $\mathrm{P}$, Dong S, Xiao J, et al. Regional inequality in health and its determinants: evidence from China. Health Policy 2010;94:14-25.

14. Lu L, Zeng J. Inequalities in the geographic distribution of hospital beds and doctors in traditional Chinese medicine from 2004 to 2014. Int J Equity Health 2018;17:165.

15. He L, Yu H, Shi L, et al. Equity assessment of the distribution of CT and MRI scanners in China: a panel data analysis. Int J Equity Health 2018;17:157.

16. Yan K, Jiang Y, Qiu J, et al. The equity of China's emergency medical services from 2010-2014. Int J Equity Health 2017;16:10.

17. Zhang $\mathrm{T}, \mathrm{Xu} \mathrm{Y,} \mathrm{Ren} \mathrm{J,} \mathrm{et} \mathrm{al.} \mathrm{Inequality} \mathrm{in} \mathrm{the} \mathrm{distribution}$ of health resources and health services in China: hospitals versus primary care institutions. Int J Equity Health 2017;16:42.

18. Fan C, Ouyang W, Tian L, et al. Elderly health inequality in china and its determinants: a geographical perspective. Int J Environ Res Public Health 2019;16:2953.

19. Zhu D, Shi X, S Nicholas, et al. Regional disparities in health care resources in traditional Chinese medicine county hospitals in China. PLoS One 2020;15:e0227956.

20. National Bureau of Statistics of China. China statistical yearbook. Beijing: China Statistics Press, 1999-2017.

21. National Health Commission of the People's Republic of China. China Health Statistics Yearbook. Beijing: Peking

doi: 10.21037/jhmhp-20-93

Cite this article as: Yang Y, Morii Y, Fujiwara K, Ishikawa T, Yamashina H, Suzuki T, Nakaya J, Ogasawara K. Trend of Gini coefficient of healthcare resources in China from 1998 to 2016. J Hosp Manag Health Policy 2021;5:40.
Union Medical College Press, 2010-2017.

22. Zhao T, Wang H. Changes of health policies in China from 2001 to 2016. China Modern Doctor 2017;24:133-5.

23. Newhouse JP. Geographic access to physician services. Annu Rev Public Health 1990;11:207-30.

24. Newhouse JP, Williams A, Bennett B, et al. Does the geographical distribution of physicians reflect market failure? Bell J Econ 1982;13:493-506.

25. Zhang H. China's health care reform should deal with the problem of "super hospital". Legal Daily. 2016. Available online: https://www.chinacourt.org/article/detail/2016/11/ $\mathrm{id} / 2359009$. shtml

26. Yao B. Should we encourage the development of "super hospital"? Capital Medicine 2009;16:28-9.

27. Zhang S. Three motions of "super hospital". China Hospital CEO 2012;20:60-3+12.

28. Bai J. When shall the boom of "super hospital" end? People's Daily. 2015. Available online: http://opinion. china.com.cn/opinion_39_131639.html

29. Long H, He Z, Tang G. Comparative analysis of the present situation of rural clinics in eastern, central and western China. Chongqing Medicine 2016;45:561-3.

30. Jin J, Wang J, Ma X, et al. Equality of medical health resource allocation in China based on the Gini coefficient method. Iran J Public Health 2015;44:445-57.

31. Zhao Y, Oldenburg B, Mahal A, et al. Trends and SocioEconomic Disparities in Catastrophic Health Expenditure and Health Impoverishment in China: 2010 to 2016. Trop Med Int Health 2020;25:236-47.

32. Wu J, Yang Y. Inequality trends in the demographic and geographic distribution of health care professionals in China: data from 2002 to 2016. Int J Health Plann Manage 2019;34:e487-508.

33. Li D, Zhou Z, Si Y, et al. Unequal distribution of health human resource in mainland China: what are the determinants from a comprehensive perspective? Int J Equity Health 2018;17:29. 